\title{
Constructing core competency indicators for clinical teachers in Taiwan: a qualitative analysis and an analytic hierarchy process
}

\author{
Ai-Tzu Li ${ }^{*}$ and Jou-Wei Lin $2,3^{*}$
}

\begin{abstract}
Background: The objective of this study was to construct a framework of core competency indicators of medical doctors who teach in the clinical setting in Taiwan and to evaluate the relative importance of the indicators among these clinical teachers.

Methods: The preliminary framework of the indicators was developed from an in-depth interview conducted with 12 clinical teachers who had previously been recognized and awarded for their teaching excellence in university hospitals. The framework was categorized into 4 dimensions: 1) Expertise (i.e., professional knowledge and skill); 2) Teaching Ability; 3) Attitudes and Traits; and 4) Beliefs and Values. These areas were further divided into 11 sub-dimensions and 40 indicators. Subsequently, a questionnaire built upon this qualitative analysis was distributed to another group of 17 clinical teachers. Saaty's eigenvector approach, or the so-called analytic hierarchy process (AHP), was applied to perform the pairwise comparisons between indicators and to determine the ranking and relative importance of the indicators.
\end{abstract}

Results: Fourteen questionnaires were deemed valid for AHP assessment due to completeness of data input. The relative contribution of the four main dimensions was 31\% for Attitudes and Traits, 30\% for Beliefs and Values, 22\% for Expertise, and 17\% for Teaching Ability. Specifically, 9 out of the 10 top-ranked indicators belonged to the "Attitudes and Traits" or "Beliefs and Values" dimensions, indicating that inner characteristics (i.e., attitudes, traits, beliefs, and values) were perceived as more important than surface ones (i.e., professional knowledge, skills, and teaching competency).

Conclusion: We performed a qualitative analysis and developed a questionnaire based upon an interview with experienced clinical teachers in Taiwan, and used this tool to construct the key features for the role model. The application has also demonstrated the relative importance in the dimensions of the core competencies for clinical teachers in Taiwan.

Keywords: Medical education, Clinical teachers, Core competency, Questionnaires, Analytic hierarchy process

\section{Background}

Medical education plays a critical role in the professional development of a physician; however, the expertise of the clinical teachers who instruct and direct medical education is rarely discussed. In today's fast-paced, technologically-advanced society, medical professionals are

\footnotetext{
* Correspondence: maggyirisli@gmail.com; jouweilin@yahoo.com 'Institute of Adult and Continuing Education, National Chung-Cheng University, 168 University Road, Min-Hsiung (621), Chia-Yi County, Taiwan ${ }^{2}$ Department of Medicine, College of Medicine, National Taiwan University, Taipei (100), Taiwan

Full list of author information is available at the end of the article
}

facing significant challenges, such as changing features of medical practice, decreased returns and increased burden, complicated working environments, and conflicting interests among doctors, patients, and payers [1]. Medical students and residents often deal with issues surrounding morals and ethics [2]. Current medical training does not provide enough education in these areas. Medical education must adapt to these changing times, and clinical teachers must lead the charge.

Despite an integrated educational reform might be needed to cultivate the new generation of physicians, only few

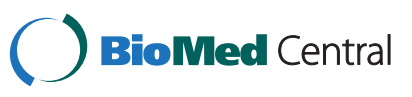


teaching methods exist in the medical education systems in Taiwan. The frequently applied teaching tools in this southeast Asian country are usually limited to: 1) basic medical classes taught in a big classroom setting; 2) small group discussions on current medical issues involving 7 or 8 medical students and a clinical teacher; and 3) clinical practice in each specialty to gain professional knowledge, skills, and experiences, and to develop and establish attitudes and values [3]. All three types of medical education contribute significantly to the development of a medical professional in Taiwan. Medical students learn to apply the theories discussed in the classroom to patients and develop attitudes toward the patients.

Hsieh, one of Taiwan's leading medical educators, stated that good clinical teachers should support an educational philosophy with enthusiasm in and devotion to teaching, and sound teaching content and methods. They play an extremely important role in cultivating appropriate professional behavior in the medical students [4]. However, it is reported that clinical teachers in Taiwan lacked teaching skills because medical schools did not have enough resources or support to facilitate improvement in their teaching. Furthermore, little was known about how to adequately evaluate their teaching performance [5]. In the meantime, only $55.9 \%$ of students were confident that they had acquired the clinical skills required to become a resident, and 70.7\% were satisfied with the quality of their medical education [6].

One of the major reasons behind this situation is that we have believed in false for a long time that medical doctors will become good teachers once they have sufficient clinical experience [7]. The core competencies required for the medical doctors who must also play a role as clinical teachers are seldom discussed. Therefore, it is urgent and important to develop a framework that incorporates both the teaching dimensions and clinical abilities that formulate the core competencies of clinical teachers in Taiwan. The objective of this study was thus to explore the components of core competency of clinical teachers in Taiwan, to develop an indicator framework of our own, and to examine the relative importance of these indicators.

\section{Methods}

We conducted a literature review on the definition and meaning of "core competency" with a focus on the job description, roles, and inner and surface characteristics of clinical teachers [8-20]. The literature review provided the lenses for analyzing the data. The methods included two stages: in-depth interview and the analytic hierarchy process (AHP). The interviews were approved by the Research Ethics Committee of National Taiwan University Hospital (IRB\# 201101050RC).

First, we conducted an in-depth interview with experienced clinical teachers in Taiwan. Those medical doctors were selected from different teaching hospitals from the northern, middle, and southern parts of Taiwan. The inclusion criteria involved 1) having clinical teaching experiences more than 3 years, 2) receiving teaching excellence awards from university hospitals or the government, and 3 ) being willing to attend the study. We first sent out invitation letters to the clinical teachers who fulfilled the criteria and obtained 12 clinical teachers. We then performed a qualitative analysis based upon the audio-taped records. Data were analyzed from the first interviewee and on an ongoing analysis. When the data was saturated, we stopped inviting interviewees [21]. Constant comparative method was utilized to analyze the data [22]. We first read the transcripts thoroughly in order to get a whole picture of the data. Then, we tried to categorize the concepts and build the relationship among categories. Further, we identified the meanings and themes from the data. We constantly compared earlier data with later ones in the data analysis process. A framework composed of four main dimensions: 1) Expertise, 2) Teaching Ability, 3) Attitudes and Traits, and 4) Beliefs and Values, sub-dimensions, and underlying indicators was established. Further, a questionnaire based upon this framework was constructed (Table 1).

In the next step, clinical teachers in five teaching hospitals in the northern, middle, and southern parts of Taiwan were invited to evaluate the professionals' questionnaires. In order to thoroughly understand the relative importance of each indicator, there were three sources of research subjects: 1) senior clinical teachers with academic reputations in the medical education domain; 2) clinical teachers who serve as the teaching-type attending doctors; and 3) teachers recommended by the Director of Teaching and Learning Development Center. Questionnaires were sent to these clinical teachers once they accepted the invitation. The questionnaires were deemed effective when all data input were complete to make pairwise comparison.

To understand the relative importance of each indicator, we adopted the analytic hierarchy process (AHP) developed by Saaty to build up a physical analysis of the relative weight of each core competency indicator for clinical teachers [23,24]. According to Triantaphyllou and Mann, "the AHP is a decision support tool which uses a multi-level hierarchical structure of objectives, criteria, subcriteria, and alternatives. The pertinent data are derived by using a set of pairwise comparisons. These comparisons are used to obtain the weights of importance of the decision criteria, and the relative performance measures of the alternatives in terms of each individual decision criterion" [25].

The questionnaires were presented by paired indicators. For each question, both sides had a factor, and the more important one was selected first by the professionals. 
Table 1 The indicator framework of core competencies for clinical teachers

\begin{tabular}{|c|c|c|}
\hline Dimensions & Sub-dimensions & Behavioral indicators \\
\hline \multirow[t]{12}{*}{ Expertise } & Clinical abilities & Being equipped with clinical knowledge \\
\hline & & Ability to make the correct judgment \\
\hline & & Possessing clinical handling ability \\
\hline & & Being familiar with clinical ethics, regulations, and systems \\
\hline & & Possessing concept of whole medicine \\
\hline & Clinical communication & Ability to explain the illness to the patient \\
\hline & & Ability to use language the patient and his/her family understands \\
\hline & & Ability to handle difficult situations \\
\hline & & Ability to clearly explain the treatment plan, including risks and benefits \\
\hline & & Ability to listen to the patient's and family's needs and demands \\
\hline & & Ability to be sympathetic to the patient and the family \\
\hline & & Ability to communicate and cooperate with the medical team \\
\hline \multirow[t]{14}{*}{ Teaching Ability } & Instructional design & Ability to set up learning goals \\
\hline & & Ability to use proper teaching methods according to learning goals \\
\hline & & Ability to arrange proper teaching content according to students' characteristics \\
\hline & Teaching skills & Ability to guide students' thoughts and discussion \\
\hline & & Ability to establish a lively and active teaching atmosphere \\
\hline & & Ability to provide examples that are close to students' experience \\
\hline & & Ability to give students chances to practice \\
\hline & & Ability to introduce clinical cases by empirical medicine method \\
\hline & Teaching material design & Designing or selecting proper teaching materials by learning goals \\
\hline & & Ability to transform clinical cases to teaching materials \\
\hline & & Ability to use multimedia teaching materials \\
\hline & Learning evaluation & Ability to collect related evaluation data \\
\hline & & Ability to use proper evaluation tools correctly \\
\hline & & Ability to review one's teaching after evaluation \\
\hline \multirow[t]{10}{*}{ Attitudes and Traits } & Teaching attitudes & Enthusiastic teaching \\
\hline & & Ability to interact well with students \\
\hline & & Ability to support and help students anytime \\
\hline & & Ability to guide students in their lives \\
\hline & Professional growth & Ability to absorb new medical information anytime \\
\hline & & Ability to take part in various kinds of teaching workshops \\
\hline & & Ability to publish research paper regularly \\
\hline & Personality traits & Being friendly and kind \\
\hline & & Patience \\
\hline & & Being confident in self-expression \\
\hline \multirow[t]{4}{*}{ Beliefs and Values } & Teaching beliefs & Ability to identify the implications and values of teaching \\
\hline & & Ability to pass on medical knowledge \\
\hline & Model teaching & Ability to teach by words and set an example \\
\hline & & Acting as a role model for young teachers \\
\hline
\end{tabular}

Then, the score scale of the relative importance (1-9) was determined. A sample question (e.g., What do you think about the relative importance of the two behavioral indicators of expertise [clinical ability and professional communication]? Please check the proper field and then determine the relative importance.) is shown in Table 2. After collecting the questionnaires, the AHP module matrix written with Excel was utilized to conduct 
Table 2 A sample question in the questionnaire

\begin{tabular}{|c|c|c|c|c|c|c|c|c|c|c|}
\hline Behavioral indicator & 1 & 2 & 3 & 4 & 5 & 6 & 7 & 8 & 9 & Behavioral indicator \\
\hline$\square$ Clinical ability & & & & & & & & & & $\square$ Professional communication \\
\hline $\begin{array}{l}\text { Note: } \\
1 \text { Equal importance. } \\
3 \text { Moderate importance } \\
5 \text { Essential or strong imp } \\
7 \text { Demonstrated importa } \\
9 \text { Absolute importance. } \\
2,4,6.8 \text { Intermediate va }\end{array}$ & ve & & & & & & & & & \\
\hline
\end{tabular}

data analysis, and each question was checked to see whether or not it met a consistency check (shown by consistency ratio, or the $C R$ values). If the $C R$ value was $<0.1$, the research result was effective [25].

\section{Results}

The framework developed by the first group of 12 clinical teachers included four dimensions (Expertise, Teaching Ability, Attitudes and Traits, and Beliefs and Values), 11 sub-dimensions, and 40 indicators (Table 1).

Another group of 25 clinical teachers in the teaching hospitals served as the AHP questionnaire evaluating professionals. After sending the invitation letters via e-mail, 17 professionals agreed to participate in this research. Sixteen of 17 questionnaires were returned (response rate $94 \%$ ), and 14 questionnaires were effective due to data completeness (return rate $87 \%$ ). Ten questionnaires came from men $(71 \%)$, and four questionnaires came from women (29\%). As for the teaching experience, one teacher taught $<5$ years $(7.1 \%) ; 4$ teachers taught between 5 and 10 years (28.6\%); 3 teachers taught between 10 and 20 years $(21.4 \%)$; and 6 teachers taught $>20$ years $(42.9 \%)$.

Matrix and weight analysis of the four dimensions of the second hierarchy (Expertise, Teaching Ability, Attitudes and Traits, and Beliefs and Values) are shown in Table 3. Among the four dimensions of clinical teachers' core competency, "Attitudes and Traits" was perceived as more important than "Beliefs and Values," "Expertise," and "Teaching Ability." The relative contribution was $31 \%, 30 \%, 22 \%$, and $17 \%$, respectively.

The sub-dimension analysis showed that in the Expertise dimension, "Clinical Communication" was perceived as more important than "Clinical Abilities" (withindimensional weight: $53 \%$ and $47 \%$, respectively) (Table $4 \mathrm{~A}$ ). Among the sub-dimensions of Teaching Ability, the relative importance was "Teaching Skills" (39\%), followed by "Instructional Design" (27\%), "Learning Evaluation” (22\%), and "Teaching Material Design" (12\%) (Table 4B). Among the sub-dimensions of Attitudes and Traits, the relative importance was "Teaching Attitudes" (50\%), followed by "Personality Traits" (26\%), and then "Professional Growth" (24\%) (Table 4C). In the dimension of Beliefs and Values, "Model Teaching" (61\%) was perceived as more important than "Teaching Beliefs" (39\%) (Table 4D).
The relative weights of all behavioral indicators beneath the 11 sub-dimensions among the four dimensions are shown in Table 5 . The 10 behavioral indicators with the highest ranks were 1) teaching by words and setting an example; 2) passing on medical knowledge; 3) acting as a role model for young teachers; 4) identifying the implications and values of teaching; 5) enthusiastic teaching; 6) ability to interact well with students; 7) ability to absorb new medical information anytime; 8) patience; 9) ability to support and help students anytime; and 10) possessing clinical handling ability. The top four indicators fell into the "Beliefs and Values" dimension; numbers 5-9 into the "Attitudes and Traits" dimension; and only number 10 into the "Expertise" dimension.

\section{Discussion}

According to Spencer \& Spencer, a competency has some components which are visible like knowledge and skills but other behavioral components like attitudes, traits, thinking styles, self-image, organizational fit etc. are hidden or beneath the surface [26]. Our work has successfully built an indicator framework to identify the components of core competency for clinical teachers in Taiwan. Similarly, the results showed that inner characteristics (i.e., attitudes, traits, beliefs, and values) are perceived as more important than surface ones (i.e., professional knowledge, skills, and teaching competency). The finding that 9 out of the top 10 indicators belonged to the two "inner characteristics" dimensions supports the assertion that instruction in areas such as attitudes and affection has a profound influence on students [4,27]. Although such intrinsic abilities had not been confirmed or measured like formal programs, [28] our research stresses the importance of "Attitudes and Traits" and "Beliefs and

Table 3 Analysis of matrix and weight of the four dimensions

\begin{tabular}{llllllll}
\hline Dimensions & & F1 & F2 & F3 & F4 & Weight & Rank \\
\hline Expertise & F1 & 1 & 2.037 & 0.645 & 0.501 & $22 \%$ & 3 \\
Teaching Ability & F2 & 0.490 & 1 & 0.516 & 0.793 & $17 \%$ & 4 \\
Attitudes and Traits & F3 & 1.547 & 1.937 & 1 & 1.067 & $31 \%$ & 1 \\
Beliefs and Values & F4 & 1.994 & 1.259 & 0.936 & 1 & $30 \%$ & 2 \\
\hline
\end{tabular}

$\mathrm{CR}=0.043<0.1$. 
Table 4 Analysis of matrix and weight of expertise dimension (panel A), teaching ability dimension (panel B), attitudes and traits dimension (panel C), and beliefs and values dimension (panel D)

\begin{tabular}{|c|c|c|c|c|c|c|c|c|}
\hline \multirow{2}{*}{$\frac{\text { Dimensions }}{\text { A. Expertise }}$} & \multicolumn{8}{|l|}{ Sub-dimensions } \\
\hline & & & $\mathrm{F} 1$ & F2 & & & Weight & Rank \\
\hline & Clinical Abilities & $\mathrm{F} 1$ & 1 & 0.885 & & & $47 \%$ & 2 \\
\hline & Clinical Communication & F2 & 1.128 & 1 & & & $53 \%$ & 1 \\
\hline \multicolumn{9}{|l|}{$C R=0<0.1$} \\
\hline \multirow[t]{5}{*}{ B. Teaching Ability } & & & $\mathrm{F} 1$ & F2 & F3 & F4 & Weight & Rank \\
\hline & Instructional Design & $\mathrm{F} 1$ & 1 & 0.865 & 1.833 & 1.209 & $27 \%$ & 2 \\
\hline & Teaching Skills & F2 & 1.154 & 1 & 3.592 & 2.029 & $39 \%$ & 1 \\
\hline & Teaching Material Design & F3 & 0.545 & 0.278 & 1 & 0.523 & $12 \%$ & 4 \\
\hline & Learning Evaluation & F4 & 0.826 & 0.492 & 1.908 & 1 & $22 \%$ & 3 \\
\hline \multicolumn{9}{|l|}{$C R=0.011<0.1$} \\
\hline \multirow[t]{4}{*}{ C. Attitudes and Traits } & & & $\mathrm{F} 1$ & F2 & F3 & & Weight & Rank \\
\hline & Teaching Attitudes & $\mathrm{F} 1$ & 1 & 2.116 & 1.986 & & $50 \%$ & 1 \\
\hline & Professional Growth & F2 & 0.472 & 1 & 0.917 & & $24 \%$ & 3 \\
\hline & Personality Traits & F3 & 0.503 & 1.089 & 1 & & $26 \%$ & 2 \\
\hline \multicolumn{9}{|l|}{$C R=0<0.1$} \\
\hline \multirow[t]{3}{*}{ D. Beliefs and Values } & & & $\mathrm{F} 1$ & $\mathrm{~F} 2$ & & & Weight & Rank \\
\hline & Teaching Beliefs & $\mathrm{F} 1$ & 1 & 0.639 & & & $39 \%$ & 2 \\
\hline & Model Teaching & $\mathrm{F} 2$ & 1.564 & 1 & & & $61 \%$ & 1 \\
\hline$C R=0<0.1$ & & & & & & & & \\
\hline
\end{tabular}

Values" as core competencies for outstanding clinical teachers.

The perceptions of these teachers in our analysis are remarkably in line with those found in studies in other populations. There have been some frameworks defining outstanding clinical teachers [8-12]. The abilities of clinical teachers can be divided into many aspects, such as teaching skills, [13] interactions with and support to students, [14,15] medical skills (including abilities to effectively demonstrate the medical history taking and physical examination skills, to discuss the recent developments within the field of medicine, and to demonstrate effective interactions with patients at the bedside and decision-making skills in group discussions), [16,17] and even other non-cognitive dimensions. For examples, the doctor-patient relationship, teacher-student relationship, and the development of an environment conducive to learning are all important skills for clinical teachers [17-19]. Clinical teachers not only have to hold a positive attitude toward young doctors and be enthusiastic about their work, [20] but they also have to be self-aware, consciously understand their influence on the resident doctors and students, and establish a good learning atmosphere [19]. Students and young doctors identify enthusiasm, compassion, openness, integrity, and good relationships with patients as attributes they seek in their role models; they are also drawn to senior figures who embody responsibility and status [20].

Sutkin et al. performed a literature review to answer the question, "What makes a good clinical teacher in medicine?" From 4,914 titles over a century, 68 articles were selected for analysis and 480 descriptors were identified. These descriptions, coming from a wide array of methodologies, including essays, surveys, qualitative analyses, and observational studies, but from very few empirical data, were grouped into 49 themes, which were clustered into three main categories: physician, teacher, and human characteristics. The authors thus concluded that excellent clinical teaching, although multi-factorial, transcends ordinary teaching and is characterized by inspiring, supporting, actively involving, and communicating with students [29]. The current research again demonstrated that being an outstanding clinical teacher depended on individual personality traits and teaching style the most, followed by what material was taught. With respect to clinical teaching, four roles and the corresponding abilities should be put into practice: 1) the role of doctor to demonstrate clinical competence; 2 ) the role of teacher to be enthusiastic about teaching and skilled at questioning and explaining; 3) the role of supervisor to encourage thinking and observe the students; and 4) the role of human to establish good teacher-student and doctor-patient relationships. 
Table 5 Weight analysis of overall indicators

\begin{tabular}{|c|c|c|c|c|c|c|c|c|}
\hline \multirow[t]{2}{*}{ Dimensions } & \multirow[b]{2}{*}{ Weight } & \multicolumn{2}{|l|}{ Sub-dimensions } & \multicolumn{5}{|l|}{ Behavioral indicators } \\
\hline & & & Weight & & Weight & Rank & $\begin{array}{l}\text { Overall } \\
\text { weight }\end{array}$ & $\begin{array}{l}\text { Overall } \\
\text { rank }\end{array}$ \\
\hline \multirow[t]{12}{*}{ Expertise } & 0.22 & Clinical abilities & 0.47 & Being equipped with clinical knowledge & 0.16 & 4 & 0.016 & \\
\hline & & & & Ability to make the correct judgment & 0.22 & 3 & 0.022 & \\
\hline & & & & Possessing clinical handling ability & 0.27 & 1 & 0.027 & 10 \\
\hline & & & & $\begin{array}{l}\text { Being familiar with clinical ethics, regulations, } \\
\text { and systems }\end{array}$ & 0.12 & 5 & 0.012 & \\
\hline & & & & Possessing concept of whole medicine & 0.23 & 2 & 0.023 & \\
\hline & & Clinical communication & 0.53 & Ability to explain the illness to the patient & 0.06 & 7 & 0.007 & \\
\hline & & & & $\begin{array}{l}\text { Ability to use language the patient and his/her } \\
\text { family understands }\end{array}$ & 0.14 & 4 & 0.016 & \\
\hline & & & & Ability to handle difficult situations & 0.09 & 6 & 0.010 & \\
\hline & & & & $\begin{array}{l}\text { Ability to clearly explain the treatment plan, } \\
\text { including risks and benefits }\end{array}$ & 0.13 & 5 & 0.015 & \\
\hline & & & & $\begin{array}{l}\text { Ability to listen to the patient's and family's } \\
\text { needs and demands }\end{array}$ & 0.2 & 1 & 0.023 & \\
\hline & & & & $\begin{array}{l}\text { Ability to be sympathetic to the patient and the } \\
\text { family }\end{array}$ & 0.19 & 2 & 0.022 & \\
\hline & & & & $\begin{array}{l}\text { Ability to communicate and cooperate with the } \\
\text { medical team }\end{array}$ & 0.19 & 2 & 0.022 & \\
\hline \multirow[t]{14}{*}{ Teaching Ability } & 0.17 & Instructional design & 0.27 & Ability to set up learning goals & 0.20 & 3 & 0.009 & \\
\hline & & & & $\begin{array}{l}\text { Ability to use proper teaching methods } \\
\text { according to learning goals }\end{array}$ & 0.27 & 2 & 0.012 & \\
\hline & & & & $\begin{array}{l}\text { Ability to arrange proper teaching content } \\
\text { according to students' characteristics }\end{array}$ & 0.53 & 1 & 0.024 & \\
\hline & & Teaching skills & 0.39 & $\begin{array}{l}\text { Ability to guide students' thoughts and } \\
\text { discussion }\end{array}$ & 0.14 & 5 & 0.009 & \\
\hline & & & & $\begin{array}{l}\text { Ability to establish a lively and active teaching } \\
\text { atmosphere }\end{array}$ & 0.16 & 3 & 0.010 & \\
\hline & & & & $\begin{array}{l}\text { Ability to provide examples that are close to } \\
\text { students' experience }\end{array}$ & 0.15 & 4 & 0.009 & \\
\hline & & & & Ability to give students chances to practice & 0.31 & 1 & 0.020 & \\
\hline & & & & $\begin{array}{l}\text { Ability to introduce clinical cases by empirical } \\
\text { medicine method }\end{array}$ & 0.24 & 2 & 0.015 & \\
\hline & & Teaching material design & 0.12 & $\begin{array}{l}\text { Designing or selecting proper teaching } \\
\text { materials by learning goals }\end{array}$ & 0.5 & 1 & 0.010 & \\
\hline & & & & $\begin{array}{l}\text { Ability to transform clinical cases to teaching } \\
\text { materials }\end{array}$ & 0.36 & 2 & 0.007 & \\
\hline & & & & Ability to use multimedia teaching materials & 0.14 & 3 & 0.002 & \\
\hline & & Learning evaluation & 0.22 & Ability to collect related evaluation data & 0.14 & 3 & 0.005 & \\
\hline & & & & Ability to use proper evaluation tools correctly & 0.26 & 2 & 0.009 & \\
\hline & & & & Ability to review one's teaching after evaluation & 0.59 & 1 & 0.022 & \\
\hline \multirow[t]{7}{*}{ Attitudes and Traits } & 0.31 & Teaching attitudes & 0.50 & Enthusiastic teaching & 0.31 & 1 & 0.049 & 5 \\
\hline & & & & Ability to interact well with students & 0.30 & 2 & 0.047 & 6 \\
\hline & & & & Ability to support and help students anytime & 0.22 & 3 & 0.034 & 9 \\
\hline & & & & Ability to guide students in their lives & 0.18 & 4 & 0.028 & \\
\hline & & Professional growth & 0.24 & Ability to absorb new medical information anytime & 0.61 & 1 & 0.045 & 7 \\
\hline & & & & $\begin{array}{l}\text { Ability to take part in various kinds of teaching } \\
\text { workshops }\end{array}$ & 0.22 & 2 & 0.016 & \\
\hline & & & & Ability to publish research paper regularly & 0.17 & 3 & 0.012 & \\
\hline
\end{tabular}


Table $\mathbf{5}$ Weight analysis of overall indicators (Continued)

\begin{tabular}{|c|c|c|c|c|c|c|c|c|}
\hline & & Personality traits & 0.26 & Being friendly and kind & 0.27 & 2 & 0.021 & \\
\hline & & & & Patience & 0.46 & 1 & 0.037 & 8 \\
\hline & & & & Being confident in self-expression & 0.27 & 2 & 0.021 & \\
\hline \multirow[t]{4}{*}{ Beliefs and Values } & 0.30 & Teaching beliefs & 0.39 & $\begin{array}{l}\text { Ability to identify the implications and values of } \\
\text { teaching }\end{array}$ & 0.48 & 2 & 0.056 & 4 \\
\hline & & & & Ability to pass on medical knowledge & 0.52 & 1 & 0.060 & 2 \\
\hline & & Model teaching & 0.61 & Ability to teach by words and set an example & 0.68 & 1 & 0.124 & 1 \\
\hline & & & & Acting as a role model for young teachers & 0.32 & 2 & 0.058 & 3 \\
\hline
\end{tabular}

When we look into the fine details among subdimensions and individual indicators, "model teaching," especially "the ability to teach by words and set an example" is widely perceived as an important component in medical education. This finding is consistent with previous research results, especially in the teacherstudent system of medical education. Teachers' behaviors and words are what the young doctors and medical students learn and imitate. Not only teachers' attitudes toward patients, but also their beliefs and values about medical work impact students' performances in the future $[27,30]$. Next, "teaching beliefs," especially "the ability to pass on medical knowledge," provides teachers with a sense of mission and is important for their identities. In addition, most interviewees mentioned that clinical teachers pass down a collection of experiences and attitudes from generation to generation [28]. Teachers with a sense of mission toward such a teaching belief will generate teaching motivation. Subsequently, the third contributing indicator was "to act as a role model for young teachers." Most interviewees considered that as clinical teachers, they needed to act in a manner for students to imitate. Duvivier et al. stated that clinical teachers were responsible for being role models for students to imitate [12]. Molodysky (2006) wrote that clinical teachers must have the potential of being role models and suggested that related training courses needed to promote such an ability [28].

Other significantly contributing indicators, including the ability to identify the implications and values of teaching, enthusiastic teaching, the ability to interact well with students, the ability to absorb new medical information anytime, patience, and the ability to support and help students anytime, belong to the dimensions of "Attitudes and Traits" or "Beliefs and Values." Hsieh thought that the meaning of medical education was to nourish young doctors and resolve patients' problems [4]. The interviewees of this research also noted that clinical teachers must recognize that teaching influences man's work, makes young doctors grow, and indirectly helps patients. Only by embracing such a teaching philosophy can teachers remain continuously enthusiastic about teaching. Hsieh,
Yang, Yen, and Molodysky all held the same point-ofview that clinical teachers' enthusiasm and devotion is extremely crucial to core competencies [4,28,31,32]. Most interviewees of this research placed such importance on teaching that they devoted their lives to teaching. Additionally, Beaudoin, Molodysky, and Sutkin all claimed that in addition to having professional medical knowledge and ability, clinical teachers needed to interact well with students [28-30]. In this research, many interviewees shared that as they tried to reach out to students and develop good teacher-student relationships, they received more positive feedback from their students. On the other hand, professional medical abilities must be improved with time to remain in touch with the demands of social change [33]. Many interviewees in this research further shared that as clinical teachers, they absorbed new information by reading medical periodicals and attending medical conferences. Furthermore, patience is also a critical characteristic for clinical teachers; they must constantly teach and remind students to keep an eye on patient safety [34]. Clinical teachers should be equipped with "supervising ability" so as to "support and help students anytime"[28]. Many interviewees in this research added that clinical teachers have to be students' supporters in their clinical work anytime and promote an environment conducive to learning.

The "clinical handling ability" is the only one among the top 10 indicators belonging to the "Expertise" dimension (generally called clinical or medical skills by most people) [33,35]. Both faculty members (clinical teachers) and residents (students) perceived "having clinical competence" as an important teaching attribute [35]. However, "Teaching Ability" and "Expertise" dimensions were perceived as less important than "Attitudes and Traits" and "Beliefs and Values." According to the Iceberg Theory, explicit skills can be developed by formal courses, but implicit skills cannot $[28,36]$.

Currently, the content of the existing clinical teachers' cultivation courses in Taiwan are mostly based on the improvement in expertise and teaching ability. However, intrinsic characteristics such as attitudes, traits, and beliefs were perceived to be more important in shaping a 
"good" clinical teacher, as the study has shown. Since these intrinsic characteristics are the outcomes of longterm socialization and have to be gradually developed through a long career-developing process, it is difficult to train medical doctors to have these inner abilities in a short period of time. Currently, all doctors in Taiwan will automatically become clinical teachers as long as they work in teaching hospitals. However, not all doctors have the intention to be teachers. Thus, initially, it might be better to recruit medical doctors who have possessed these valued components and their expertise and teaching ability could be obtained through training or formal courses. In the long run, we might need to uncover and enhance "dormant abilities" by incorporating these valued elements into the curriculum early in the medical school so that the awareness of becoming a clinical teacher should be implanted in the early stage of career development in a medical professional.

The strength of the study is that these indicators could not only serve as the self-assessment tool for clinical teachers to enhance or strengthen teaching effectiveness and quality, but also serve as a guideline for careerdevelopment facilitators to design teaching workshops or train-the-trainer programs. However, since the participants were obtained from a relatively homogeneous group of Taiwanese excellent teachers in the university medical centers and we only used interview as the major data-collecting method, we suggest that in the future research, the clinical teachers from different levels of teaching hospitals should be included, and other methodologies, such as observation, could also be utilized in order to triangulate the data.

\section{Conclusion}

This study developed the components for and demonstrated the relative importance of the core competencies for clinical teachers in Taiwan. The experts regard intrinsic characteristics (attitudes, traits, beliefs, and values) as more important than surface ones (professional knowledge and skills, and teaching competency). These ideas should foster dialogue for changes among clinical teachers, hospital managers, and the medical community.

\section{Competing interests}

The authors declared no competing interests.

\section{Authors' contribution \\ ATL obtained funding for this project and participated in study concept and design, acquisition of data, analysis and interpretation of data, and drafting of manuscript. JWL involved in data collection, drafting of the manuscript, critical revision and editing of the manuscript, and study supervision. Both authors read and approved the final manuscript.}

\section{Acknowledgements}

This study was supported by grants from the National Science Council, Taiwan (NSC98-2511-S-194-004-). We would like to thank Ms. Hui-Jung Kuo for her assistance.

\section{Author details}

'Institute of Adult and Continuing Education, National Chung-Cheng University, 168 University Road, Min-Hsiung (621), Chia-Yi County, Taiwan. ${ }^{2}$ Department of Medicine, College of Medicine, National Taiwan University, Taipei (100), Taiwan. ${ }^{3}$ Department of Internal Medicine, National Taiwan University Hospital Yun-Lin Branch, 579 Yun-Lin Road, Section 2, Dou-Liou City (640), Yun-Lin County, Taiwan.

Received: 25 July 2013 Accepted: 3 April 2014

Published: 11 April 2014

\section{References}

1. American College of Physicians: Solutions to the Challenges Facing Primary Care Medicine, Policy Monograph. Philadelphia: American College of Physicians; 2009. Available from American College of Physicians, $190 \mathrm{~N}$. Independence Mall West, Philadelphia, PA 19106.

2. Barry $\mathrm{D}$, Cyran $\mathrm{E}$, Anderson RJ: Common issues in medical professionalism: room to grow. Am J Med 2000, 108(2):136-142.

3. Chou JY, Chiu CH, Lai E, Tsai D, Tzeng CR: Medical education in Taiwan. Med Teach 2012, 34(3):187-191.

4. Hsieh BS: General Medicine Education (1st edition). Taipei, Taiwan: National Taiwan University College of Medicine; 2003.

5. Huang KY, Lai CW: Taiwan White Paper for Medical Education. Taipei: Ministry of Education; 2003. Available on http://cmfd.csmu.edu.tw/ezcatfiles/cmfd/ img/img/447/128344863.pdf [Chinese] Last retrieved on April 13, 2014.

6. Chan WP, Wu TY, Hsieh MS, Chou TY, Wong CS, Fang JT, Chang NC, Hong $C Y$, Tzeng CR: Students' view upon graduation: a survey of medical education in Taiwan. BMC Med Educ 2012, 12:127.

7. Chu TS, Weed HG, Wu CC, Hsu HY, Lin JT, Hsieh BS: A programme of accelerated medical education in Taiwan. Med Teach 2009, 31(3):e74-e78.

8. Irby DM: Clinical teacher effectiveness in medicine. J Med Educ 1978, 53(10):808-815.

9. Irby D, Rakestraw P: Evaluating clinical teaching in medicine. J Med Educ 1981, 56(3):181-186.

10. Irby DM, Ramsey PG, Gillmore GM, Schaad D: Characteristics of effective clinical teachers of ambulatory care medicine. Acad Med 1991, 66(1):54-55.

11. Ramsbottom-Lucier MT, Gillmore GM, Irby DM, Ramsey PG: Evaluation of clinical teaching by general internal medicine faculty in outpatient and inpatient settings. Acad Med 1994, 69(2):152-154.

12. Duvivier RJ, van Dalen J, van der Vleuten CP, Scherpbier AJ: Teacher perceptions of desired qualities, competencies and strategies for clinical skills teachers. Med Teach 2009, 31(7):634-641.

13. Molenaar WM, Zanting A, van Beukelen P, de Grave W, Baane JA, Bustraan $J A$, Engbers R, Fick TE, Jacobs JC, Vervoorn JM: A framework of teaching competencies across the medical education continuum. Med Teach 2009, 31(5):390-396.

14. Paukert JL, Richards BF: How medical students and residents describe the roles and characteristics of their influential clinical teachers. Acad Med 2000, 75(8):843-845.

15. Oslen B: How reasons for entry into the profession illuminate teacher identity development. Teach Educ Q 2008, 35(3):23-40.

16. Wright SM, Kern DE, Kolodner K, Howard DM, Brancati FL: Attributes of excellent attending-physician role models. N Engl J Med 1998, 339(27):1986-1993.

17. Irby DM: Clinical teaching and the clinical teacher. J Med Educ 1986, 61(9 Pt 2):35-45.

18. Wright SM, Carrese JA: Excellence in role modelling: insight and perspectives from the pros. CMAJ 2002, 167(6):638-643.

19. Weissmann PF, Branch WT, Gracey CF, Haidet P, Frankel RM: Role modeling humanistic behavior: learning bedside manner from the experts. Acad Med 2006, 81(7):661-667.

20. Paice E, Heard S, Moss F: How important are role models in making good doctors? BMJ 2002, 325(7366):707-710.

21. Strauss AL, Corbin JM: Basics of Qualitative Research: Grounded Theory Procedures and Techniques. Newbury Park, CA: SAGE Publications; 1990.

22. Lincoln YS, Guba EG: Naturalistic Inquiry. Beverly Hills CA: Sage Publications; 1985.

23. Saaty TL: Decision Making for Leaders; The Analytical Hierarchy Process for Decisions in a Complex World, Belmont, CA: Wadsworth, Translated to French, Indonesian, Spanish, Korean, Arabic, Persian, and Thai, latest edition, revised. Pittsburgh: RWS Publications; 2000. 
24. Saaty T: Decision making with the analytic hierarchy process. Int I Services Sciences 2008, 1(1):83-98

25. Triantaphyllou E, Mann SH: Using the analytic hierarchy process for decision making in engineering applications: some challenges. Int J Ind Eng 1995, 2(1):35-44.

26. Spencer LM, Spencer SM: Competency at Work. New York: John Wiely \& Sons; 1993.

27. Rose GL, Rukstalis MR, Schuckit MA: Informal mentoring between faculty and medical students. Acad Med 2005, 80(4):344-348.

28. Molodysky E, Sekelja N, Lee C: Identifying and training effective clinical teachers-new directions in clinical teacher training. Aust Fam Physician 2006, 35(1-2):53-55.

29. Sutkin $G$, Wagner $E$, Harris I, Schiffer R: What makes a good clinical teacher in medicine? A review of the literature. Acad Med 2008, 83(5):452-466.

30. Beaudoin C, Maheux B, Cote L, Des Marchais JE, Jean P, Berkson L: Clinical teachers as humanistic caregivers and educators: perceptions of senior clerks and second-year residents. CMAJ 1998, 159(7):765-769.

31. Yang $\mathrm{JH}$, Chen JY: The importance of role models in medical education: everyone should be a good role model. J Med Edu 2006, 10:8-15.

32. Yeh HT, Xu DF, Chen YJ: The impact of clinical teachers on medical education (臨床教師對全人醫學教育的觀感與省思). [Chinese] J Healthcare Qual 2010, 4:17-22.

33. Wu MJ, Chen YH, Hsieh ZY, Chen DY, Sheu HH, Lan JL: Core competency of clinical teachers. (臨床教師應具備之核心能力) [Chinese]. J Healthcare Qual 2010, 4:70-74.

34. Li AT: Teamwork climate and patient safety attitudes: associations among nurses and comparison with physicians in Taiwan. J Nurs Care Qual 2013, 28(1):60-67.

35. Buchel TL, Edwards FD: Characteristics of effective clinical teachers. Fam Med 2005, 37(1):30-35.

36. Maurer TJ, Wrenn KA, Pierce HR, Tross SA, Collins WC: Beliefs about 'improvability' of career-relevant skills: relevance to job/task analysis, competency modelling, and learning orientation. J Organ Behav 2003, 24(1):107-131

doi:10.1186/1472-6920-14-75

Cite this article as: Li and Lin: Constructing core competency indicators for clinical teachers in Taiwan: a qualitative analysis and an analytic hierarchy process. BMC Medical Education 2014 14:75.

\section{Submit your next manuscript to BioMed Central and take full advantage of:}

- Convenient online submission

- Thorough peer review

- No space constraints or color figure charges

- Immediate publication on acceptance

- Inclusion in PubMed, CAS, Scopus and Google Scholar

- Research which is freely available for redistribution 